\title{
Reterritorialização, ciberespaço e novas-velhas práticas espaço-temporais no capitalismo esguio de Zygmunt Bauman
}

\section{Reterritorialization, cyberspace and new-old spatio-temporal practices in Zygmunt Bauman's slender capitalism}

\author{
BERNARDO JOÃO DO REGO MONTEIRO MOREIRA ${ }^{1}$
}

Neste ensaio, discutiremos o tema do capitalismo esguio e sua relação com o período que dá nome ao livro de Zygmunt Bauman: a modernidade leve ou líquida. Propondo uma reflexão crítica, iremos articular a análise com a produção teórica de Gilles Deleuze e Félix Guattari sobre a máquina capitalista e os processos de desterritorialização e reterritorialização, enquanto apresentamos os caminhos dessa análise conjugada com a discussão sobre o ciberespaço e as novas-velhas práticas espaço-temporais engendradas em sua arquitetura em constante transformação.

Bauman apresenta o processo de constituição da modernidade leve enquanto uma ruptura progressiva com a modernidade pesada. A modernidade pesada (dos hardware, das grandes máquinas, dos enormes volumes), ao acelerar a emancipação do tempo pelo encurtamento das distâncias, vai à conquista territorial do espaço. A cruzada pelo poder e pela devoração do espaço se articula diante do paradigma do controle: a defesa vigilante do que está dentro das fronteiras. Lá dentro, o tempo é rotina, é homogêneo, é rígido. Mas com a neutralização do tempo, capital e trabalho passam a se digladiar na imobilidade congelada da fábrica fordista. A modernidade pesada sucumbe então para a culminação de seu processo: a modernidade leve (BAUMAN, 2011).

A adaptabilidade e a fluidez do capitalismo de software tentam incessantemente superar a dinâmica conflituosa da coexistência no espaço, tornando o trabalho descorporificado e deixando o capital livre: o espaço tende então à nulidade, não pode mais frear o tempo. Com esse tempo quase-instantâneo, virulento e sem limites, o lugar perde seu valor. $O$ infinito fluido enterra então a solidez e a durabilidade, antigos pilares da humanidade. Essa tendência - que ainda não chegou a seu fim leva a possibilidade de um tempo que, ao aniquilar o espaço, aniquila a si mesmo (BAUMAN, 2011). Tal limite implica práticas espaço-temporais cada vez mais emancipadas em relação a seus referenciais físicos. Entretanto, com a crescente expansão do ciberespaço, um movimento extremamente complexo se apresenta, articulando a tendência elucidada por Bauman com uma contratendência inseparável desse processo.

\footnotetext{
${ }^{1}$ Bernardo João do Rego Monteiro Moreira é pesquisador pelo Programa Institucional de Bolsas de Iniciação Científica do $\mathrm{CNPq} / \mathrm{UFF}$, pesquisador vinculado ao Grupo de Análise em Política Internacional (GAPI) - PPGCP/UFF e graduando em Ciências Sociais pela Universidade Federal Fluminense. E-mail: bemoreira@id.uff.br.
} 
A ideia de ciberespaço é conceptualizada como um lugar, espaço das comunicações em uma rede digital de computadores. Lugar, portanto, que não se limita a fronteiras geográficas e territoriais e funda um novo limiar entre o espaço virtual e o mundo da materialidade clássica, dominada essencialmente pelo concreto, pela fronteira física (ALLEN, LASTRA, 2020). Tal estatuto está plenamente de acordo com a tendência apontada por Bauman: a emancipação do espaço cibernético em relação ao tempo e espaço físicos demonstra os novos territórios onde o capital esguio habita, molda e atravessa. Por outro lado, a indicação que Deleuze e Guattari apontam sobre as tendências do capitalismo nos indicam as mudanças que o ciberespaço sofre em seu desenvolvimento: "A tendência só tem limite interno e ela não para de ultrapassá-lo, deslocando-o, isto é, reconstituindo-o, reencontrando-o como limite interno a ser novamente ultrapassado por deslocamento..." (DELEUZE, GUATTARI, 2011)

Essa reconstituição deslocada do limite nos permite compreender o movimento de desterritorialização do capitalismo e sua relação com o processo de transformação arquitetônica do ciberespaço. Enquanto a arquitetura do ciberespaço tende a um ciber-libertarianismo pela sua formação e funcionamento análogo a uma terra nullius supra-territorial (um espaço livre de regulações governamentais), a questão técnica se encontra atravessada por questões geopolíticas complexas. Mesmo com tal arquitetura de alta distribuição dinâmica e descentralizada, o sonho ciber-libertário de uma internet como bem global declinou progressivamente. Timmers (2019) atribui tal problema a um defeito essencial: o design determinante para o funcionamento da internet é deficitário de segurança e privacidade. Além disso, houve um impacto inesperado da internet sobre a economia e sociedade, resultando em uma capitulação da rede por empresas oligopolistas, cibercriminosos e governos. O ciberespaço é como um continente recém-descoberto pronto para ser dividido entre os atores geopolíticos ou é como os oceanos, além da possibilidade de um controle soberano? (TIMMERS, 2019; ALLEN, LASTRA, 2020).

O paradigma westfaliano é fundado na reivindicação de uma comunidade com poder independente e exclusivo de legislação sobre um território definido, formando instituições políticas estatais que incorporam a autoridade soberana. Com essa jurisdição nacional, constitui-se uma delimitação social legalmente constituída do espaço físico como uma fronteira invisível, tendo marcos físicos só como referência. Constitui-se então o espaço soberano como um território absoluto e homogêneo de fronteiras contíguas que não se sobrepõem, como ilhas de autoridade que demarcam o dentro e o fora (LOH, HEISKANEN, 2020; ALLEN, LASTRA, 2020).

A fronteira entre o ciberespaço e o 'mundo real' não é uma clara fronteira entre o físico e o virtual. É uma fronteira permeada por objetos invisíveis, estruturas jurídicas, infraestruturas tecnológicas fisicamente situadas e interações institucionais em espaços abstratos; entre abstrações e abstrações materialmente incorporadas em 
uma realidade social mediada por tecnologia. A militância do capitalismo esguio contra as estruturas duráveis passa a se deparar com obstáculos que deslocam a tendência desterritorializante do ciberespaço a um endurecimento de seus segmentos e formas arquitetônicas. Os livres fluxos de dados passam a ser canalizados em linhas mais rígidas, em decorrência do processo onde o ciber-utopianismo da ausência de fronteiras cibernéticas é contraposto com um processo de extensão da soberania territorial para o ciberespaço (LOH, HEISKANEN, 2020; ALLEN, LASTRA, 2020; BAUMAN, 2001; DELEUZE, GUATTARI, 1996).

Com a soberania estatal se assentando sobre o ciberespaço, a internet se desmembra em uma splinternet. Testemunha-se progressivamente então um processo de territorialização parcial do ciberespaço por meio de mecanismos de segurança e vigilância, já que a independência soberana deste não é mais expressivamente reconhecida por nenhum país. A tendência de fronteiras defensivas no ciberespaço para a demarcação de um ciberespaço nacional ciber-soberano se concretiza em um novo ciber-mundo westfaliano com fronteiras virtuais. Independente dos elementos físicos do ciberespaço que exigem uma sede localizada geograficamente, a arquitetura técnica torna-se cada vez mais governada por estruturas soberanas apesar de sua estrutura originalmente livre e descentralizada (GOODNIGHT, HONG, 2019; TIMMERS, 2019; KHANNA, 2018; BARAM, MENASHRI, 2019).

O capitalismo esguio de Bauman constitui então sua própria contratendência. Entretanto, não se trata de uma instância transcendente ao processo ou um contragolpe do Estado. Pelo contrário, há uma imanência da atividade de antiprodução na própria produção, um freio dos fluxos descodificados estreitamente ligado a liberação dos fluxos; uma axiomática que acrescenta mais axiomas e desarranja-se para impedir a saturação do sistema. É esse o processo que define o capitalismo: o que ele desterritorializa de um lado, ele reterritorializa de outro (Deleuze, Guattari, 2011). Tal elemento é essencial para a ampliação de sua escala: a reterritorialização do ciberespaço reintroduz artificialmente o modelo arcaico da soberania westfaliana, fundando os processos de construção da ciber-soberania. Emerge então uma arquitetura maleável que se torna endurecida; os livres fluxos de dados que atravessam o mundo em frações de segundo passam a ser reintegrados ao ciberespaço nacional (DELEUZE, GUATTARI, 1996).

Tal noção ressoa na conceptualização de Tiqqun sobre o aparelho cibernético que encarna a autoridade enquanto tal: "a circulação máxima coincide com o controle máximo. Nada se move sem ser incontestavelmente 'livre' e ao mesmo tempo estritamente registrado, identificado e individuado em arquivos exaustivos de registros digitais" (TIQQUN, 2011). Essa formulação está presente de forma similar em Deleuze e Guattari, quando afirmam que "é a própria conjunção de fluxos 
desterritorializados que desenha neo-territorialidades arcaicas ou artificiais" (DELEUZE, GUATTARI, 2011).

As novas práticas espaço-temporais se revelam novas-velhas práticas: o neoarcaísmo de Morin nos permite analisar como tais neo-territorialidades se fundam na reintegração residual de fragmentos de códigos, em que o paradigma da soberania westfaliana é ressuscitado para conter os fluxos descodificados do ciberespaço sem fronteiras. Com a ciber-soberania, o ciberespaço deixa de ser um oceano recémdescoberto e se torna análogo ao continente africano em seu processo de partilha, com recortes reterritorializados para organizar os segmentos e impedir a fuga dos fluxos (DELEUZE, GUATTARI, 2011; ALLEN, LASTRA, 2020).

Essa transformação não significa, entretanto, o bloqueio total dos fluxos descodificados, do processo de desterritorialização e da tendência líquida. Se trata, por outro lado, de uma concentração dos fluxos, círculos e pontos notáveis da rede em um referente central, um movimento onde os círculos tornam-se concêntricos. $\mathrm{O}$ espaço de fluxos e o tempo intertemporal de Castells, que ressoa na virtualidade da modernidade líquida de Bauman, passa a ser canalizado pelos segmentos geométricos duros do território ciber-soberano, binarizados em função do dentro e do fora. Tal centro de ressonância, que organiza e totaliza seus elementos de forma molar, não se constitui pelo conflito com os fluxos moleculares, mas os sobrecodifica em função de sua segmentaridade dura: os fluxos de dados do ciberespaço mantêm-se "livres", mas suas trajetórias são marcadas pelos registros dos servidores centrais com seus bancos de dados em nuvens (DELEUZE, GUATTARI, 1996; BAUMAN, 2001; CASTELLS, 1999).

O capitalismo esguio que sobrevoava o vasto oceano cibernético sem fronteiras constrói agora as paredes pelas quais os fluxos de dados serão comprimidos. O recorte geométrico das fronteiras nacionais volta à cena em uma reterritorialização arcaica, que reintroduz no ciberespaço aspectos da modernidade pesada, como aparelhos estatais de controle e vigilância. A tendência líquida de Bauman não se esgotou, mas agora permeia com seus fluxos as novas estruturas ciber-soberanas.

\section{Referências}

ALLEN, J. G.; LASTRA, R. M. “Border problems: mapping the third border". In: The modern law review, vol. 83, no 3, jan/2020, p. 505-538, 30 .

BARAM, G.; MENASHRI, H. "Why can't we be friends? Challenges to international cyberwarfare cooperation efforts and the way ahead”. Comparative Strategy, vol. 38, no 2, mar/2019, p. 89-97.

BAUMAN, Z. Modernidade líquida. Rio de Janeiro: Zahar, 2001.

DELEUZE, G.; GUATTARI, F. Mil platôs - capitalismo e esquizofrenia (vol. 3). Rio de Janeiro: 34, 1996.

DELEUZE, G.; GUATTARI, F. O anti-Édipo. Rio de Janeiro: 34, 2011. 
HONG, Y.; GOODNIGHT, G. T. "How to think about cyber sovereignty: the case of China". In: Chinese journal of communication, vol. 13, no 1, 12 nov/2019, p. 8-26.

KHANNA, P. "State sovereignty and self-defence in cyberspace". In: Brics law journal, vol. 5, no 4, 15 dez/2018, p. 139-154.

LOH, D. M. H.; HEISKANEN, J. "Liminal sovereignty practices: rethinking the inside/outside dichotomy”. In: Cooperation and conflict, vol. 55, № 3, 9 mar/2020, p. 284304.

TIMMERS, P. “Challenged by “digital sovereignty"”. In: Journal of internet law, vol. 23, (6), 2019, p. 1-20.

TIQQUN. This is not a program. Los Angeles: Semiotext(e), 2011.

Submissão: 07. 06. 2021

Aceite: 25. 09. 2021 